\title{
Editorial
}

\section{Fiona Poland}

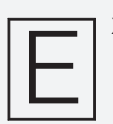

xamining interventions to improve well-being.

Advances in care provision, scientific discovery and policies in the 20th century encouraged changes in attitudes to ageing, which admitted the potential for people to enhance their wellbeing while ageing and to actively seek ways to do this. The articles in the current issue remind us how this is a continuous process of incremental and cumulative horizon-scanning, innovation and testing out in practice.

Although we are increasingly encouraged to promote exercise as a promoter of health in ageing, we are less often given information to detail the mechanisms through which exercise might also improve the health of people living with dementia. The unique and useful systematic review of physical activity interventions produced by Pringle et al. is therefore most timely in identifying their specific effects on neurological structure or endocrinal markers and, importantly, how they may positively slow cognitive decline to indicate a well-evidenced case for promoting such interventions. Their findings also point to the greater benefit of incorporating such activities over the longer term into lifestyles rather than introducing short, sharp bursts of one-off or isolated exercise programmes.

The many transitions which older people can encounter in bodily changes, lifestyles and places of living may greatly challenge peoples' abilities to create culturally acceptable and worthwhile narratives for themselves and others in making sense and value about their selves from these changes. Schneible, Gabriel and Bradt offer a reflective practice paper on helping older residents in a long-term nursing home to understand and re-present such changes as movement through transitional stages and liminalities, which can be modulated to be experienced very differently through music therapy. They describe how this can support people to engage ritual transformation to reinterpret and then perform their own healing processes to culturally inform practice.

Re-appreciating the nature of the relationships through which care is given and supported is encouraged by the "ecological approach" illustrated in the work reported by Donnellan, Bennett and Watson. They compare the resilience characteristics for carers that different kinship caring relationships may generate. The challenges for carers, almost inevitably increasing over time and then resilience-encouraging resources they experienced as being made available them in context, are vividly presented through carers' own words and then the authors' consideration of their contexts of living. They argue that an ecological approach helps understand how and why such resilience-encouraging resources may be interactively made available through some reciprocal relationships but not others partly in relation to the ecology of, more or less supportive, communities.

The potential of attending to the relationality of care, including in hospital care for people with dementia is evidenced by Petty et al. who then identify feasible solutions to some of the seemingly intransigent and recurrent challenges for staff to address the emotional needs of people with dementia in hospital settings. Their interview study with a purposive sample of 12 nurses working in two long-stay wards draws out lessons these staff were able to formulate given their in-depth understanding of the challenges of providing good care for this group of patients. The authors have but reiterate the importance of being able to offer personalised
Fiona Poland is based at the School of Health Sciences (HSC), University of East Anglia, Norwich, UK. 
rather than depersonalised care with this group of patients, partly by prioritising emotional well-being alongside other priorities of care, actively seeking out sufficient personal information about each patient, valuing good teamwork and more effective information sharing. The authors have provided a useful table of recommended actions for improving emotional well-being for this group within hospital settings.

In each of these articles, the lessons found through developing progressive interventions remind us that we live together in a context of innovation and that close examination of knowledge-building around interventions continues to help us to identify and promote supportive relationships and ecological factors that can dynamically enhance ageing and older lives.

For instructions on how to order reprints of this article, please visit our website: www.emeraldgrouppublishing.com/licensing/reprints.htm

Or contact us for further details: permissions@emeraldinsight.com 